\title{
Prediction of Phase Separation in Silicate Glass for the Creation of Value-added Materials from Waste Slag
}

\author{
Masanori SUZUKI and Toshihiro TANAKA \\ Division of Materials and Manufacturing Science, Graduate School of Engineering, Osaka University, 2-1 Yamadaoka, Suita, \\ 565-0871 Osaka, Japan.
}

(Received on April 17, 2006; accepted on July 12, 2006)

\begin{abstract}
A thermodynamic evaluation was performed to predict phase separation in multi-component oxide glasses. Composition ranges for metastable liquid-liquid immiscibility and spinodal decomposition in a $\mathrm{SiO}_{2}-$ $\mathrm{CaO}-\mathrm{MgO}-\mathrm{Na}_{2} \mathrm{O}$ quaternary system were calculated on the assumption that glasses in the oxide system can be regarded as super-cooled liquid phases. Some experimental studies on two-phase separation of glasses were carried out to confirm the thermodynamic evaluation of the phase separation. Microstructures in heat-treated glass samples were observed by transmission electron microscopy, to investigate the development of interconnected microstructures in the glass with increased heating temperatures and holding times, and spinodal decomposition of glass was indicated.
\end{abstract}

KEY WORDS: spinodal decomposition; $\mathrm{SiO}_{2}-\mathrm{CaO}-\mathrm{MgO}-\mathrm{Na}_{2} \mathrm{O}$ system; Gibbs energy; thermodynamic databases; super-cooled liquid phase.

\section{Introduction}

In recent years, recycling of waste slag has become a serious issue because large amounts of slag are discharged from metallurgical and incinerated ash melting processes.

In general, slag can easily be transformed into glass because of its high viscosity. The present study focused on the phase separation of glass as one specific characteristic of glass. Phase separation has been found to occur in various oxide glasses $^{1-5)}$ and porous glasses obtained from spinodal decomposition have been investigated in detail for specific oxide systems. ${ }^{5,6)}$ Since those porous glasses have three-dimensionally interconnected porous structures in which the pore size can be easily controlled at a nano-scale level, glasses obtained from spinodal decomposition are expected to have widespread applications, for example as filters to trap impurities in water. Thus, slag may be transformed into value-added functional glass materials.

To generate phase separation in glass from waste slag, the composition ranges for immiscibility as well as spinodal decomposition have to be evaluated for multi-component slag systems. Previous experimental studies have empirically found metastable miscibility gaps for various binary or ternary oxide systems. ${ }^{2-5)}$ For multi-component oxide systems such as waste slag, it is difficult to predict metastable immiscibility empirically, although there are some experimental studies on phase separation. ${ }^{7)}$ Therefore, it is necessary to perform a thermodynamic evaluation to determine phase separation in multi-component oxide systems. No attempts have been made to estimate metastable immiscibility boundaries in multi-component oxide systems on the basis of thermodynamic analyses, although some thermodynamic databases have been developed to evaluate phase equilibria and other thermodynamic properties. $^{8)}$

In this paper, a thermodynamic approach is used to predict metastable phase separation in multicomponent oxide systems, using the condition that the glass in oxide systems is regarded as a super-cooled liquid phase. $\mathrm{A} \mathrm{SiO}_{2}-\mathrm{CaO}-$ $\mathrm{MgO}-\mathrm{Na}_{2} \mathrm{O}$ quaternary system was selected for the evaluation of phase separation because $\mathrm{SiO}_{2}, \mathrm{CaO}$ and $\mathrm{MgO}$ are fundamental components of general waste slag, and $\mathrm{Na}_{2} \mathrm{O}$ allows $\mathrm{SiO}_{2}-\mathrm{CaO}-\mathrm{MgO}$ slag to melt at a low temperature. The composition ranges for phase separation and spinodal decomposition are estimated from the composition dependence of the Gibbs energy curves in the super-cooled liquid phase, which are calculated from the $\mathrm{F}^{*} \mathrm{~A} * \mathrm{C}^{*} \mathrm{~T}$ thermodynamic databases for molten oxide systems. ${ }^{8)}$ In addition, spinodal decomposition of glasses is investigated experimentally to confirm the above evaluation of phase separation.

\section{Estimation Procedure for Miscibility Gap and Com- position Range for Spinodal Decomposition}

In the present work, the possibility of phase separation including spinodal decomposition was evaluated on the assumption that glasses in slag systems can be regarded as "super-cooled liquid phases." Gibbs energies and activities of $\mathrm{SiO}_{2}$ in the metastable liquid phase of oxide systems were calculated with the FactSage thermodynamic computing system ${ }^{8)}$ for the prediction of the metastable miscibility gaps.

Liquid-liquid phase separation is generally evaluated from the Gibbs energy curve of the liquid phase. Figure 1(a) shows the Gibbs energy curve in the liquid phase for 


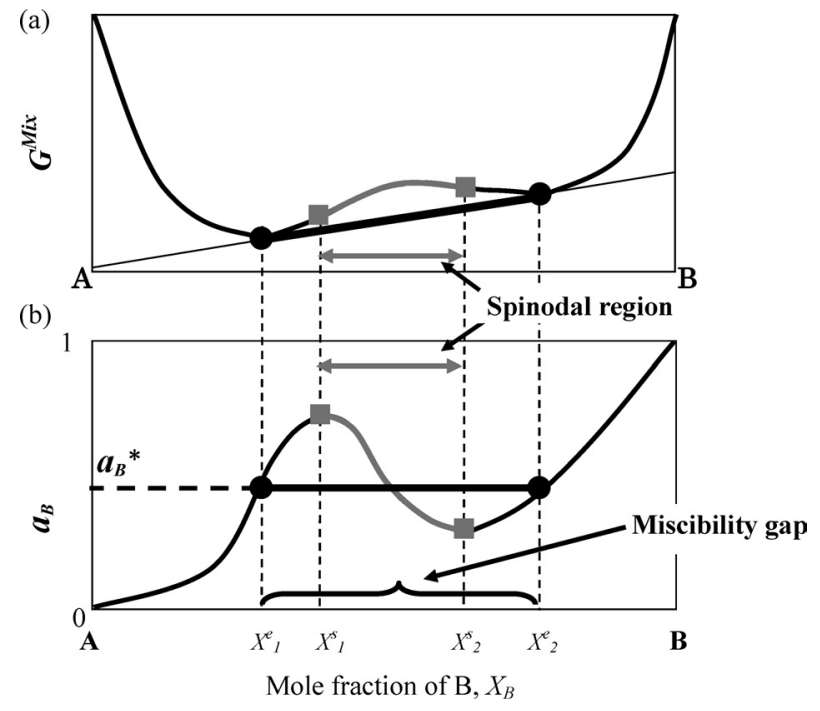

Fig. 1. Schematic diagram of (a) free energy curve of the liquid phase, (b) activity curve of component B in the case of phase separation.

an A-B binary system in the case of phase separation. As shown in Fig. 1(a), the miscibility gap is determined from two points of contact on the Gibbs energy curve with a common tangent. The composition range for spinodal decomposition, referred to as the "spinodal region" in the present paper, is obtained from two inflexion points in the Gibbs energy curve.

In this paper metastable miscibility gaps in multi-component oxide systems are calculated by the FactSage thermodynamic computing program. ${ }^{8}$ However, for the evaluation of spinodal regions it is necessary to calculate Gibbs energies of the liquid phase, because spinodal regions are not obtained directly from the FactSage program.

It should be noted that Gibbs energy curves of general oxide melts tend to change linearly with composition in the case of phase separation. ${ }^{9)}$ In this study, the composition dependence of the Gibbs energies of the liquid phase is calculated for several binary silicate systems. Figure 2(a) shows the calculated results for Gibbs energies in a $\mathrm{SiO}_{2}-\mathrm{CaO}$ system. It is found from Fig. 2(a) that the calculated Gibbs energies change linearly with the concentration of $\mathrm{SiO}_{2}$, even at low temperatures, and this means that it may be difficult to accurately evaluate immiscibility in general silicate systems from the Gibbs energy curves.

On the other hand, it is known that the evaluation of activities is often valid for determining liquid-liquid miscibility gaps in oxide systems. ${ }^{10)}$ In the present study, the composition dependence of the activity of $\mathrm{SiO}_{2}$ was calculated, to estimate the composition ranges for spinodal decomposition definitively. Figure 1(b) shows the activity curve of component B for an A-B binary system. In the case of phase separation, an activity curve has both maximum and minimum points at certain compositions. To determine the composition range for spinodal decomposition, differentiation of the activity with respect to composition was calculated by the following Eq. (1):

$$
\frac{\partial a_{\mathrm{B}}}{\partial X_{\mathrm{B}}}=\frac{\exp \left(\mu_{\mathrm{B}} / R T\right)}{R T} \cdot \frac{\partial \mu_{\mathrm{B}}}{\partial X_{\mathrm{B}}}=\left(1-X_{\mathrm{B}}\right) \frac{a_{\mathrm{B}}}{R T} \cdot \frac{\partial^{2} G^{\mathrm{Mix}}}{\partial X_{\mathrm{B}}^{2}}
$$
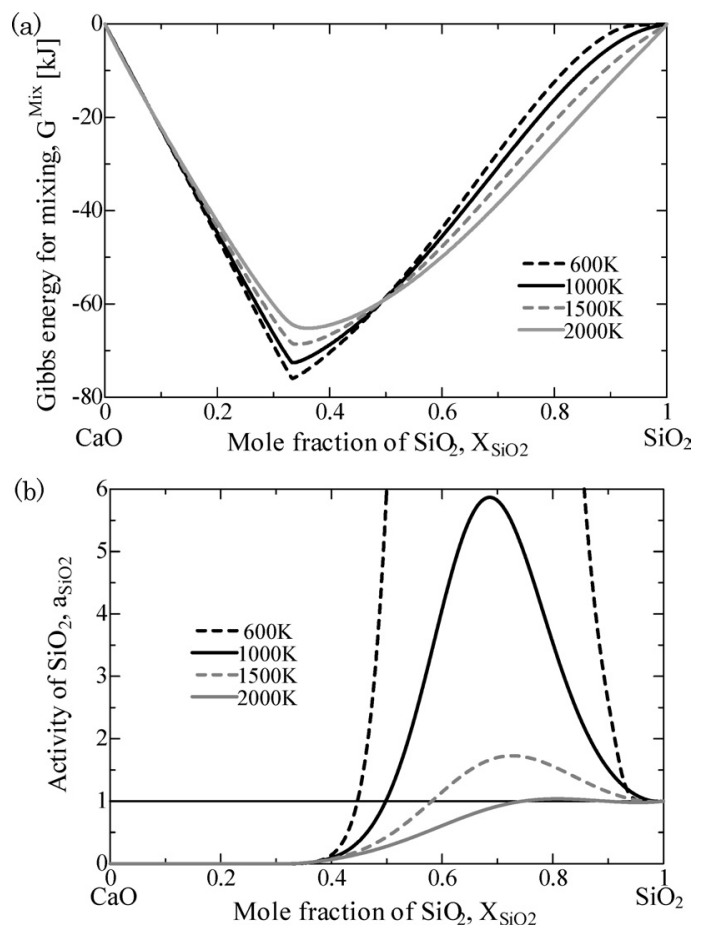

Fig. 2. Calculated (a) Gibbs energies for mixing, (b) activities of $\mathrm{SiO}_{2}$ in $\mathrm{SiO}_{2}-\mathrm{CaO}$ system (with respect to the pure liquid standard state).

where $X_{\mathrm{B}}$ is the mole fraction of component B and $G^{\mathrm{Mix}}$ represents the Gibbs energy for mixing in the liquid phase. $\mu_{\mathrm{B}}$ and $a_{\mathrm{B}}$ denote the chemical potential and activity, respectively, of component B, and are calculated from Eq. (2) with respect to the pure liquid standard state:

$$
\mu_{\mathrm{B}}=R T \ln a_{\mathrm{B}}=G^{\mathrm{Mix}}+\left(1-X_{\mathrm{B}}\right) \frac{\partial G^{\mathrm{Mix}}}{\partial X_{\mathrm{B}}} \ldots \ldots \ldots
$$

Equation (1) indicates that the first differential of the activity with respect to the concentration of $\mathrm{B}$ is directly proportional to the second differential of the Gibbs energy with respect to composition. Since the second composition derivative of the Gibbs energy becomes zero at its inflexion points, the spinodal region is determined from the extremum points on the activity curve.

The estimation procedure for spinodal regions described above can easily be extended to ternary or multi-component systems if one of the separated phases is a pure component. Figure 2(b) shows the calculated results for activities of $\mathrm{SiO}_{2}$ in a $\mathrm{SiO}_{2}-\mathrm{CaO}$ system at various temperatures. The activity of $\mathrm{SiO}_{2}$ has minimum point at the composition close to pure $\mathrm{SiO}_{2}$, and this result indicates that one of the separated phases in the metastable liquid-liquid immiscibility region is regarded as pure $\mathrm{SiO}_{2}$ liquid phase.

Figure 3 shows a schematic diagram of the miscibility gap and spinodal region for an $\mathrm{A}-\mathrm{B}-\mathrm{C}$ ternary system. The spinodal region where pure component $\mathrm{A}$ constitutes one equilibrium phase is evaluated by calculating activities of component $\mathrm{A}$ across the straight lines drawn in Fig. 3 with constant composition ratios of components $\mathrm{B}$ to $\mathrm{C}$, which correspond to tie-lines in the immiscibility region in the ternary system. For quaternary or multi-component systems, spinodal region is evaluated similarly by calculating activi- 


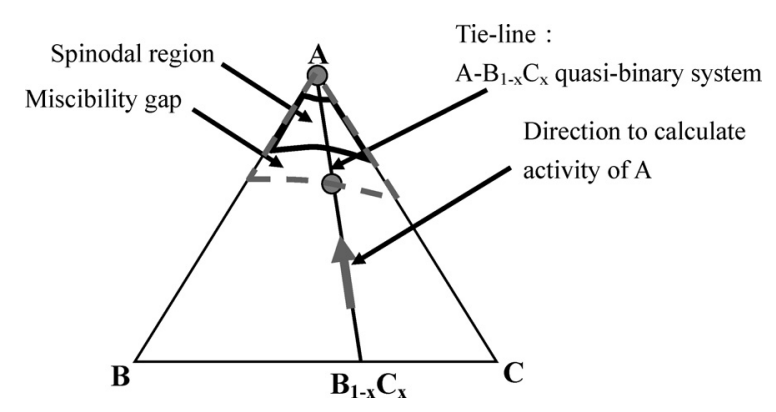

Fig. 3. Schematic diagram of miscibility gap and spinodal region in a ternary system in the case where one of separated phases is pure A liquid.

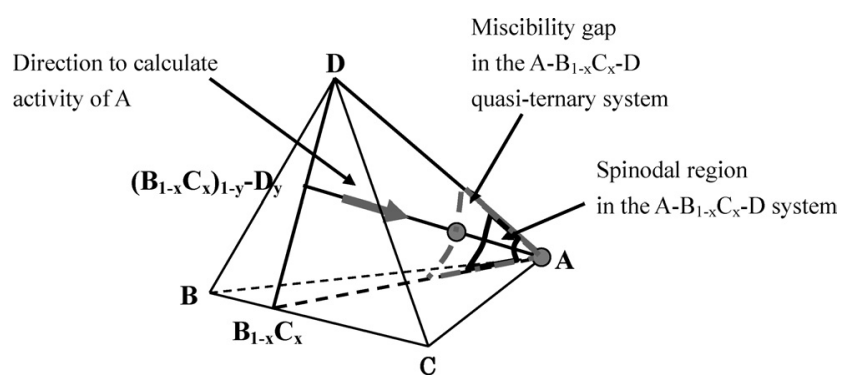

Fig. 4. Schematic diagram of miscibility gap and spinodal region in a quasi-ternary system in the case where one of separated phases is pure $\mathrm{A}$ liquid.

ties of $\mathrm{A}$ in $\mathrm{A}-\mathrm{B}_{1-x} \mathrm{C}_{x}-\mathrm{D}$ quasi-ternary systems ( $x$ is 0 to 1 ), as illustrated in Fig. 4.

In this paper, miscibility gaps in a $\mathrm{SiO}_{2}-\mathrm{CaO}-\mathrm{MgO}-$ $5 \mathrm{~mol} \% \mathrm{Na}_{2} \mathrm{O}$ quasi-ternary system were calculated by the FactSage thermodynamic computing program. Spinodal regions in the system described above were estimated by calculating activities of $\mathrm{SiO}_{2}$ in $\mathrm{SiO}_{2}-(\mathrm{CaO})_{1-x}(\mathrm{MgO})_{x}-\mathrm{Na}_{2} \mathrm{O}$ ( $x$ is 0 to 1 ) quasi-ternary systems.

\section{Experimental Procedure}

The occurrence of phase separation by spinodal decomposition was investigated experimentally to verify the calculated results for the metastable miscibility gaps. Silicon dioxide, magnesium oxide, sodium carbonate and calcium carbonate (all provided by Waco Corp. as special grade chemicals) were used to make glass materials.

First, $70 \mathrm{SiO}_{2}-30$ mass $\% \mathrm{Na}_{2} \mathrm{O}$ glass was prepared as a mother glass to prevent the evaporation of $\mathrm{Na}_{2} \mathrm{O}$ at a high temperature. Silicon dioxide and sodium carbonate were mixed in a mortar and melted in a Pt $-10 \% \mathrm{Rh}$ crucible in air for $3 \mathrm{~h}$ at $1373 \mathrm{~K}$. The mother glass was made by quenching the melt in water. X-ray diffraction analysis was carried out on the glass using a Rigaku RINT $2500 \mathrm{~V}$ with $\mathrm{CuK} \alpha$ radiation at $40 \mathrm{kV}, 200 \mathrm{~mA}$, to examine whether a glass phase was obtained.

$\mathrm{SiO}_{2}-\mathrm{CaO}-\mathrm{MgO}-\mathrm{Na}_{2} \mathrm{O}$ glasses were prepared using silica, magnesia, calcium carbonate and the $70 \mathrm{SiO}_{2}-30$ mass $\% \mathrm{Na}_{2} \mathrm{O}$ mother glass. These materials were mixed in a mortar and melted in Pt- $10 \% \mathrm{Rh}$ crucibles in air for $5 \mathrm{~h}$ at $1873 \mathrm{~K}$. Glass samples were obtained by quenching the melts in water and they were examined by X-ray diffraction analysis to determine whether they were glassy or not. The glasses were then heat-treated in air at a given temperature between $873 \mathrm{~K}$ and $948 \mathrm{~K}$, and then cooled to room temperature. X-

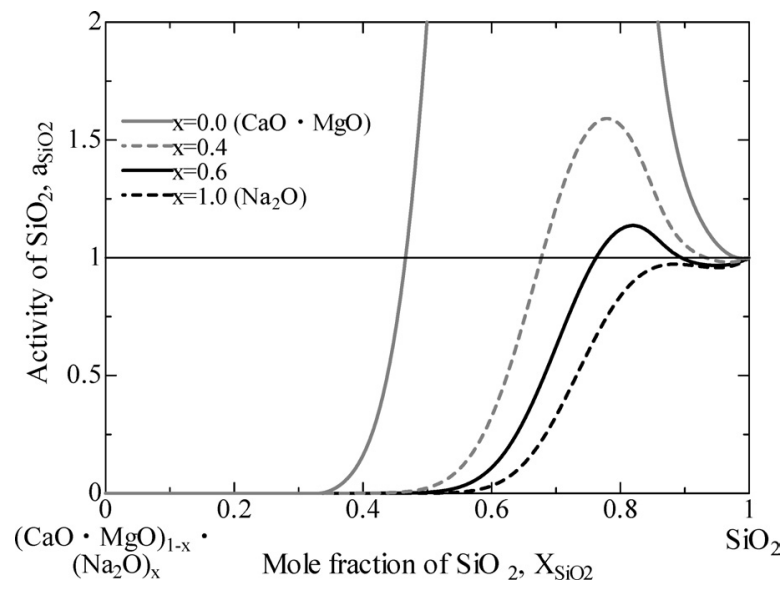

Fig. 5. Calculated activities of $\mathrm{SiO}_{2}$ at $873 \mathrm{~K}$ in the $\mathrm{SiO}_{2}-(\mathrm{CaO}$. $\mathrm{MgO})-\mathrm{Na}_{2} \mathrm{O}$ system.

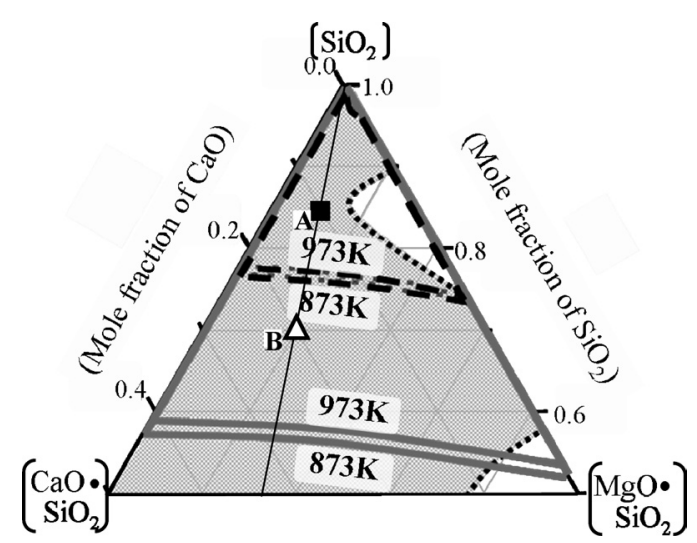

Fig. 6. Estimated composition ranges for phase separation and spinodal decomposition in the $\mathrm{SiO}_{2}-\mathrm{CaO}-\mathrm{MgO}-$ $5 \mathrm{~mol} \% \mathrm{Na}_{2} \mathrm{O}$ system (solid lines: immiscibility boundaries, dashed lines: spinodal lines, dotted lines: phase boundaries at $1773 \mathrm{~K}$, hatched area: liquid phase at $1773 \mathrm{~K}$, square and triangle marks: compositions used in the present experimental work).

ray diffraction analysis was again performed on the heattreated glasses to determine whether they retained their glass state. Microstructures in these glasses were observed by a HITACHI H800 transmission electron microscope using an excitation voltage of $200 \mathrm{kV}$. All observations were made at 50000 and 100000 magnifications. Preparation of the samples for electron microscopy was performed using both Ar-ion milling and the ultrasectioning method.

\section{Results and Discussion}

\subsection{Calculated Results for the Composition Ranges for Phase Separation}

Figure 5 shows the calculated activities of $\mathrm{SiO}_{2}$ at $873 \mathrm{~K}$ in the super-cooled liquid phase of the $\mathrm{SiO}_{2}-\mathrm{CaO}-\mathrm{MgO}-$ $\mathrm{Na}_{2} \mathrm{O}$ quaternary system. In Fig. 5, activities of $\mathrm{SiO}_{2}$ are calculated with varying concentrations of $\mathrm{SiO}_{2}$ while keeping constant molar composition ratios of $\mathrm{CaO}$ to $\mathrm{MgO}$ as 1.0. For any composition ratio of $\mathrm{Na}_{2} \mathrm{O}$ to $(\mathrm{CaO} \cdot \mathrm{MgO})$, the activity of $\mathrm{SiO}_{2}$ has minimum point at a very silica-rich composition, and these results suggest the occurrence of phase separation where one of the separated phases can be regarded as a pure $\mathrm{SiO}_{2}$ metastable liquid phase.

The calculated results for the metastable miscibility 
Table 1. Compositions of glass samples used in the experiment.

\begin{tabular}{l|c|c|c|c}
\hline & \multicolumn{4}{|c}{ Composition [mol\%] } \\
\cline { 2 - 5 } & $\mathrm{SiO}_{2}$ & $\mathrm{CaO}$ & $\mathrm{MgO}$ & $\mathrm{Na}_{2} \mathrm{O}$ \\
\hline Glass A & 80.8 & 9.5 & 4.7 & 5.0 \\
\hline Glass B & 66.5 & 19.0 & 9.5 & 5.0 \\
\hline
\end{tabular}

Table 2. Change in appearance of glasses A by heat treatment.

\begin{tabular}{c|c|cc|ccc}
\hline \multirow{2}{*}{$\begin{array}{c}\text { Temperature } \\
{[\mathrm{K}]}\end{array}$} & \multicolumn{5}{|c}{ Heating time $[\mathrm{h}]$} \\
\cline { 2 - 6 } & 24 & \multicolumn{2}{|c|}{48} & 96 & 192 \\
\hline 873 & transparent & $\rightarrow$ & transparent & $\rightarrow$ & transparent \\
\hline 923 & transparent & $\rightarrow$ & bluish transparent & $\rightarrow$ & adularescent \\
\hline 948 & bluish transparent & $\rightarrow$ & adularescent & $\rightarrow$ & opalescent \\
\hline
\end{tabular}

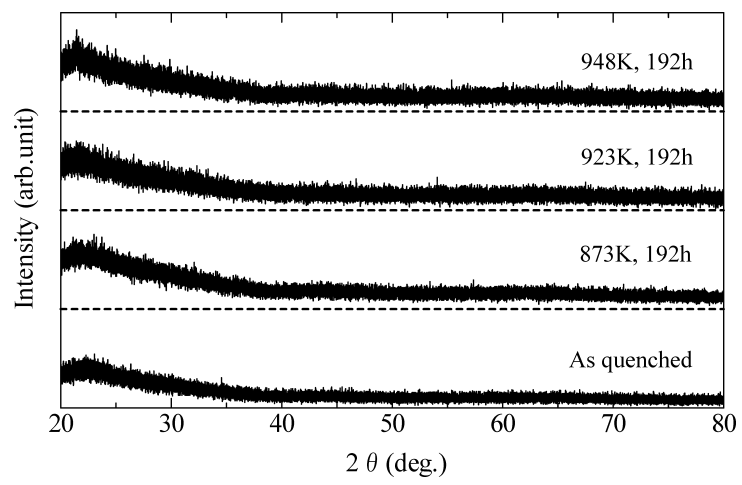

Fig. 7. X-ray diffraction patterns of heat-treated glasses A.

gaps and the spinodal regions of the $\mathrm{SiO}_{2}-\mathrm{CaO}-\mathrm{MgO}-$ $5 \mathrm{~mol} \% \mathrm{Na}_{2} \mathrm{O}$ system are shown in Fig. 6, where the sum of the molar concentrations of all components except $\mathrm{Na}_{2} \mathrm{O}$ is converted to unity. In Fig. 6, the calculated immiscibility boundaries and spinodal lines are represented by solid lines and dashed lines respectively. Phase boundaries at $1773 \mathrm{~K}$ were additionally calculated with the $\mathrm{F}^{*} \mathrm{~A} \mathrm{C}^{*} \mathrm{~T}$ oxide databases $^{8)}$ and are shown in this phase diagram by dotted lines. It is found from Fig. 6 that some parts of the spinodal regions overlap in the liquid area, of which the liquidus is below $1773 \mathrm{~K}$, in the $\mathrm{SiO}_{2}-\mathrm{CaO}-\mathrm{MgO}-5 \mathrm{~mol} \% \mathrm{Na}_{2} \mathrm{O}$ system.

\subsection{Experimental Results for Phase Separation in the Predicted Spinodal Region}

The occurrence of phase separation by spinodal decomposition was investigated for the glass A having composition indicated by a square mark in Fig. 6. Glass B, having composition indicated by a triangle mark in Fig. 6, was also selected to compare a microstructure in heated glasses having this composition with that in glass A. Those compositions were selected because glass samples with those compositions can easily be made from liquid oxide, whose liquidus are below $1773 \mathrm{~K}$ as described above. The selected compositions are shown in Table $\mathbf{1 .}$

Table 2 shows the change in the appearance of the glass A with holding time at different heating temperatures. As the heating temperature increased, glasses rapidly turned opaque. Figure 7 shows X-ray diffraction patterns for glasses A heated for $192 \mathrm{~h}$ at different temperatures. Since crystalline peaks were not detected in the X-ray diffraction patterns, the opaqueness was not attributed to crystalliza-

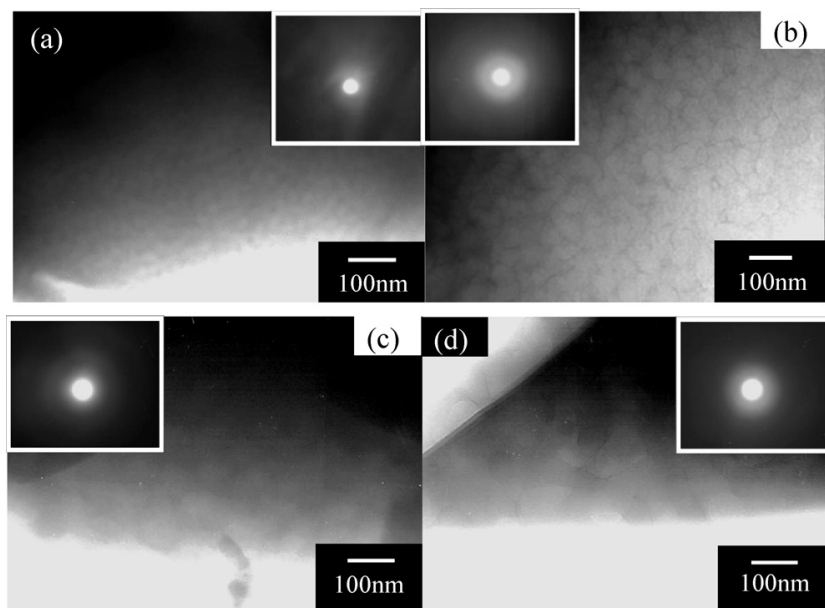

Fig. 8. Electron micrographs showing effect of temperature on glasses A: (a) untreated; (b) $873 \mathrm{~K}, 192 \mathrm{~h}$; (c) $923 \mathrm{~K}$, 192 h; (d) 948 K, 192 h.
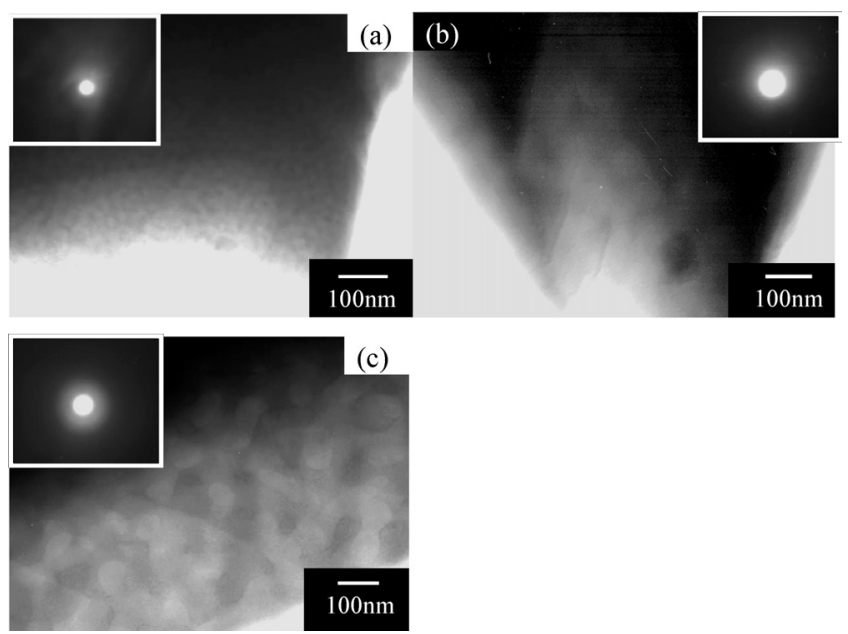

Fig. 9. Electron micrographs showing effect of time on glasses A: (a) untreated; (b) 948 K, 96 h; (c) 948 K, 192 h.

tion of glass.

Electron micrographs of glasses A after heat treatments for $192 \mathrm{~h}$ at various temperatures are shown in Fig. 8. Development of a morphology with interconnectivity was observed as the heating temperature increased. The cross-section of the modulated structure is estimated to be 80 to $100 \mathrm{~nm}$ in diameter in the sample heated for $192 \mathrm{~h}$ at $948 \mathrm{~K}$. The interconnected structure was also found to grow with holding time, as shown in Fig. 9.

Figure 10 shows an electron micrograph of glass B heated for $192 \mathrm{~h}$ at $948 \mathrm{~K}$, comparing with the microstructure in glass A after heat treatment on the same condition as described above. The small particle structure was observed in glass B with the composition out of spinodal regions, and this structure is different from the interconnected structure observed in glass A having composition included in spinodal regions.

The above experimental results indicate that the interconnected structure observed in glass A results from phase separation of glasses by spinodal decomposition, and that metastable liquid-liquid immiscibility occurs in accordance with the thermodynamic prediction of miscibility gaps. It is expected that these interconnected microstructures obtained from spinodal decomposition of glass can be used to create 


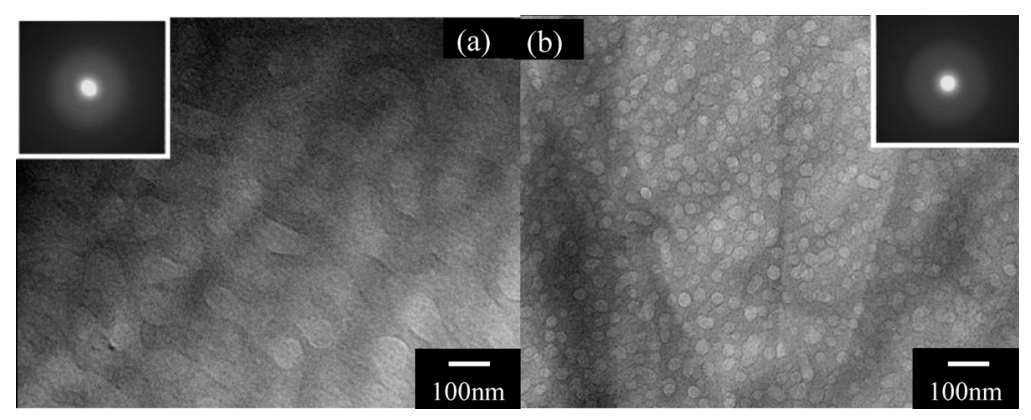

Fig. 10. Comparison between microstructures of heat-treated glasses: (a) glass A, $192 \mathrm{~h}$ at $948 \mathrm{~K}$; (b) glass B, $192 \mathrm{~h}$ at $948 \mathrm{~K}$.

value-added porous glasses by selectively leaching out one of the separated phases using acid.

\section{Conclusions}

A thermodynamic analysis was performed to evaluate metastable phase separation in multi-component oxide systems on the assumption that glasses in oxide systems can be regarded as super-cooled liquid phases. Metastable miscibility gaps and spinodal lines were calculated for a $\mathrm{SiO}_{2}-$ $\mathrm{CaO}-\mathrm{MgO}-\mathrm{Na}_{2} \mathrm{O}$ quaternary system using the $\mathrm{F}^{*} \mathrm{~A}^{*} \mathrm{C}^{*} \mathrm{~T}$ oxide databases. ${ }^{8)}$

Experimental studies on the occurrence of spinodal decomposition of glasses were carried out to confirm the calculated results for the metastable immiscibility boundaries. Interconnected structures, which are not related to the crystallization of glasses, were observed in heat-treated glasses in the predicted composition ranges for spinodal decomposition. Furthermore, the effects of both heating temperatures and holding times on the interconnected structure were observed in the heat-treated glasses described above. Consequently, it has been found that the composition range for spinodal decomposition can be evaluated for multi-component oxide systems by using thermodynamic databases.

\section{Acknowledgements}

Observation of the microstructures in the samples by transmission electron microscopy was supported by assistant professor Yuichiro Koizumi (Department of Adaptive Machine Systems, Osaka University) and assistant professor Takeshi Nagase and technical official Wataru Fujitani (Division of Materials and Manufacturing Science, Osaka University) and technical official Eiji Taguchi (Research Center for Ultra-High Voltage Electron Microscopy, Osaka University). We thank them most warmly for their assistance in this study.

\section{REFERENCES}

1) Y. Utsumi, S. Sakka and M. Tashiro: Glass Technol., 11 (1970), 80.

2) D. G. Burnett and R. W. Douglas: Phys. Chem. Glasses, 11 (1970), 125.

3) W. Haller, D. H. Blackbarn and J. H. Simmons: J. Am. Ceram. Soc., 57 (1974), 120.

4) T. P. Seward, D. R. Uhlmann and D. Turnball: J. Am. Ceram. Soc., 51 (1968), 278.

5) T. H. Elmer, M. E. Nordberg, G. B. Carrier and E. J. Korda: J. Am. Ceram. Soc., 53 (1970), 171.

6) Eliezer M. Rabinovich, M. Ish-Shalom and A. Kisilev: J. Mater. Sci., 15 (1980), 2027.

7) T. Nakajima and Y. Kuroki: Nippon Kagaku Kaishi, (1981), 1231.

8) C. W. Bale, A. D. Pelton, W. T. Thompson and G. Eriksson: FactSage, Ecole Polytechnique, Montreal, http://www.crct.polymtl. ca. (accessed on March 20, 2006)

9) P. F. James: J. Mater. Sci., 10 (1975), 1802.

10) H. Gaye and J. Welfringer: Proc. 2nd. Int. Symp. Metall. Slags and Fluxes, TMS-AIME, Warrendale, PA, (1984), 357. 